\author{
Л.В. Кобликова
}

\title{
ОСОБЕННОСТИ ТЕЛЕСНОЙ ИДЕНТИФИКАЦИИ ДЕТЕЙ ДОШКОЛЬНОГО ВОЗРАСТА, ВОСПИТЫВАЮЩИХСЯ В РАЗНЫХ СОЦИАЛЬНЫХ УСЛОВИЯХ
}

\begin{abstract}
Аннотация. В статье описаны специфика формирования личности у детей-сирот дошкольного периода детства, описана роль телесной идентификации в самосознании ребёнка и вред хронического мышечного напряжения, подчёркнута значимость свободы движений, умения расслабляться, знать и показывать на себе все части тела, распознавать мимику других людей. Предметом исследования является телесная идентификация дошкольников. Цель работы: описание особенностей телесной идентификации детей, воспитывающихся в детских домах, по сравнению с теми, кто растёт в условиях семьи. В качестве методов исследования использовались опросник "Моё лицо и тело», методики "Собери человека из отдельных частей», "Одень куклу» и стандартизованное наблюдение в трёх ситуациях. Результаты исследования показывают, что для большинства детей-сирот свойственны проблемы ориентировки в пространстве, трудности физического развития; слабое развитие навыков самообслуживания. Менее половины из них могут самостоятельно указать части лица и тела. Примерно у половины детей-сирот зафиксирован средний и низкий уровень развития телесных реакций, что может свидетельствовать о серьёзных проблемах телесной идентичности. Направления практической психологической помощи таким детям обсуждаются. Ключевые слова: идентичность, тело, мышечное напряжение, телесная идентификация, движение, мимика, развитие личности, дошкольный возраст, сироты, задержка психического развития.

Abstract. In her research Koblikova describes peculiarities of personality development of preschool orphans, the role of physical identity in a child's self-awareness, and negative consequences of chronic muscle tension and emphasizes the importance of free movement, relaxation skills, ability to say and point out body parts and to understand facial expression of others. The subject of the research is the formation of physical identity of preschool children. The purpose of the research is to describe specifics of physical identity of children living in orphanages compared to children who grow up in the family environment. The researcher has ued psychodiagnostic methods ("My face and body»; "Make a Person out of Body Parts», "Dress Up a Doll») and standardized observation (free play, organized outdoor game and tactile contact during the massage). The results show that the majority of orphans have a distorted sense of location, difficulties of physical development; and poor development of self-help skills. Less than half of them can specify the parts of their face and body. Approximately half of the orphans have demonstrated average and low levels of development of physical reactions that may indicate serious problems of physical identity. Directions of practical psychological assistance to these children are discussed.
\end{abstract}

Key words: mental retardation, preschool age, personal development, facial expression, movement, physical identity, muscle tension, orphans, body, identity.

\section{Актуальность формирования телесной идентификации в дошкольном возрасте}

В современном обществе происходят глобальные трансформационные процессы, касающиеся самых разных его аспектов: от демографических до социокультурных и социально-психологических. В этих условиях вопрос формирования гармоничной личности, всесторонне развитого, образованного, сознательного представителя нации, обретает особую актуальность, так как именно такое поколение будет укреплять общество и государство. Личностная зрелость основывается на личностной идентичности, которая включает в себя именную, социальную, полоролевую и телесную идентификации. В центре нашего исследования оказался последний указанный её тип. Развитие здоровой телесной идентификации затрагивает сразу две актуальные области: область здоровья нации и область психологического благополучия личности. 
Формирование телесной идентификации берёт своё начало в раннем детстве, а его результаты сказываются на всей последующей жизни человека. Если в детстве ребёнок научился хорошо осознавать своё тело, положительно относиться к нему, то в будущем это выразится в бережном и аккуратном отношении к телу, к своему физическому здоровью. Человек, уважительно относящийся к телу, редко страдает от пищевых расстройств, предпочитает заниматься спортом для укрепления мышц и поддержания хорошей физической формы, адекватно воспринимает сигналы со стороны своего тела, указывающие на необходимость своевременного обращения к врачу. Этим людям характерен высокий уровень ответственности за своё здоровье.

Более того, человек, который в детстве усвоил необходимость бережного отношения к своему телу, как правило, так же бережно относится и к телу и здоровью других людей. Вследствие этого вероятность того, что он причинит физический вред другому лицу, сводится к минимуму. Будучи взрослыми, такие люди умеют построить воспитание своих детей, избегая телесных наказаний. Таким образом, формирование здоровой телесной идентификации может стать одним из средств борьбы с всемирно разрастающейся проблемой семейного насилия.

Актуальность в области психологического благополучия личности обусловлена большой значимостью идентификационных процессов в формировании самооценки, удовлетворения своей жизнью, степени ответственности за своё поведение, умении успешно функционировать в социальном пространстве и др.

Согласно Э. Эриксону, становление идентичности является главным событием жизни человека, которое нужно рассматривать, как накопление внутренней целостности и уверенности на ранних этапах онтогенеза, что находит реальное воплощение в последующей жизни [1].

\section{Специфика формирования личности у детей сирот дошкольного возраста}

Крайне важно понимать, как именно происходит становление идентичности. В норме телесная идентичность формируется посредством эмоционально-телесного общения с родителями и близкими родственниками. Это подчёркивает исключительную роль мамы и папы в формировании образа тела ребёнка. Н.Е. Татаринцева, отмечает, что в 3 года у ребёнка происходит идентификация «физического образа Я», усваиваются те или иные внешние половые различия [2]. В этот период важно присутствие обоих родителей, так как именно в сравнении ребёнок познает морфологические отличия в строении тела разных людей, и на основе этого переходит на осознанный анализ своего тела. Отсутствие хотя бы одного из родителей существенно усложняет и затягивает процесс идентификации, а отсутствие обоих ещё больше усугубляет эту проблему. Кроме того, дети-сироты сталкиваются с неизбежным дефицитом нравственных критериев при оценке своего тела, взаимоотношений между полами, недифференцированностью образцов женского и мужского поведения и др.

В 5-6 лет дети идентифицируются с родителем своего пола, а в 6-7 лет происходит половая дифференциация установок и интересов [3]. Успешное прохождение половой идентификации обусловлено наличием положительного социально-эмоционального опыта дошкольника с родителями, наблюдениями за поведением взрослых. Сиротство - это фактор, разрушающий эмоциональные связи ребёнка, который вызывает психические, физические, социально культурные и личностные нарушения.

Сиротство обуславливает появление различных деформаций в психическом, физическом и социальном развитии ребёнка. Эти деформации связаны с депривацией его нужд в психическом и социальном аспектах. Новообразованием дошкольного возраста, согласно В.С. Мухиной и Е.Е. Кравцовой, выступает соподчинение мотивов, а, следовательно, и произвольная регуляция поведения и контроль эмоций [3; 4]. Дети-сироты, зажатые в эмоциональной депривации, с одной стороны, и социальной, с другой, сталкиваются с проблемами личностного развития.

По Л.С. Выготскому, в дошкольном возрасте появляется эгоцентрическая речь, т.е. речь, обращённая к себе, а не к социальному окружению [5]. Она имеет большое значение в вопросе овладения собственным поведением, самоконтролем. Учитывая тот факт, что в этот период также происходит соподчинение мотивов, можно говорить о том, что именно в дошкольном возрасте закладываются основы саморегуляции и осознания себя как самостоятельного и уникального субъекта. Именно в дошкольном возрасте берет свое начало формирование самосознания и самооценки. Самосознание предполагает осознание своего тела и формирование телесной идентичности.

\section{Место телесной идентификации в самосознании личности ребёнка}

В случае благоприятного прохождения процесса телесной идентификации развивается положи- 


\section{Психология и психотехника 2(89) • 2016}

тельное отношение к своему телу, бережное отношение к своему физическому здоровью, восприятие целостного телесного образа, положения тела в пространстве, осознание эмоционального напряжения в теле и умение им управлять, расслаблять мышечные зажимы. Позитивное отношение к своему телу закладывает основу позитивного отношения к самому себе в целом [6].

Ребёнок формирует образ Я, начиная с образа своего тела. Момент, когда он понимает, что его мама и он - отдельно существующие субъекты, связан именно с пониманием отдельности существования их тел: «это тело мамы, а это тело моё». О процессах сепарации и индивидуации, телесной идентификации в раннем возрасте много писали Д.В. Винникотт, М. Малер, Р. Шпиц и др. При этом все авторы согласны с тем, что формирование самосознания начинается с осознания ребёнка отдельности существования своего тела [7; 8; 9].

Образ тела выступает главным компонентом формирования самосознания ребёнка. Он обеспечивает репрезентацию опыта телесного самоощущения в процессе взаимодействия личности со значимыми другими людьми. Все функции тела - движения, ритмы, состояния, ощущения - не могут быть отделены от социальной жизни. Человек движется и ощущает окружающий мир, включаясь в познавательные, коммуникативные и символические процессы [10].

Согласно О.В. Залесской, большое значение в развитии ребёнка имеет его реакция на тепло. В норме тело реагирует на тепло удовольствием расслабляется, раскрывается, приобретает плавность и т.д. Неспособность принять тепло (как физическое, так и психическое) может рассматриваться как тревожный симптом [11].

В. Райх выделил 7 сегментов тела, где могут быть сосредоточены участки хронически напряжённых мышц, или мышечные блоки, сковывающие свободное течение энергии в теле, и соответствующую им проблематику [12].

С напряжением в глазном сегменте автор соотносил существование страхов, связанных с отношениями (страх агрессии, конфликта, оценки, обиды и др.), в оральном сегменте - трудности с вербализацией, выражением эмоций, сопровождающих плач, агрессивные укусы, сосание и гримасы; неспособность кричать, плакать и др. С напряжением в шейном сегменте соотносились проблемы, вызванные сдерживанием злости или плача. Напряжение в грудном сегменте, согласно В. Райху, появляется в связи с подавлением любых эмоций, сильных желаний и переживаний; хроническим самоконтролем и сдерживанием; тревожностью. С напряжением 8 диафрагмальном сегменте связаны проблемы с подавлением удовольствия или тревоги, отвращения; неспособность отвергать или удаляться от неприятного в окружающем мире; проблемы воли. Напряжение в брюшном сегменте вызывается подавлением злости, страха нападения, а в тазовом - подавлением тревоги, гнева или удовольствия, опасений, связанных с инстинктом самосохранения; блокированием сексуального возбуждения [12; 13].

Н.А. Берштейн считал, что телесная идентичность, поведение и отношение к социуму развивается на основании детско-родительских отношений и реализуется за счёт работы нескольких уровней, которые порождают целый спектр движений и определяют смысловую структуру действий. В реализацию технических компонентов движений входят тонус, иннервации, реципрокное торможение, сложные синергии [14].

1. Рубро-спинальный уровень палеокинетических регуляций $\boldsymbol{A}$. Иногда уровень $\boldsymbol{A}$ из фонового становится ведущим, запускающим или тормозящим весь процесс личностной интеграции.

2. Уровень синергии и штампов или таламо-паллидарный уровень $\boldsymbol{B}$. Обеспечивает движения выразительной мимики, пантомимы и пластики, т.е. совокупность не символических, а непосредственно эмоциональных движений.

3. Пирамидно-стриарный уровень пространственного поля $\boldsymbol{C}$. Движения уровня $\boldsymbol{C}$ несут, давят, тянут, берут и т.д.

4. Теменно-премоторный уровень действий $\boldsymbol{D}$. Уровень $\boldsymbol{D}$ почти монопольно принадлежит человеку.

5. Уровни, лежащие выше уровня действий (группа $\boldsymbol{E}$ ). С этим уровнем связаны все разновидности речи и письменности; музыкальное, театральное и хореографическое исполнение. $\boldsymbol{E}$ - ведущий уровень, создающий мотив для двигательного акта и осуществляющий его основную смысловую корреляцию приведение результата в соответствие с намерением.

Подводя итог, можно сказать, что начиная с раннего возраста, становление телесной идентификации неразрывно связано с гармоничным развитием личности в целом.

Проблема становления телесной идентификации у детей дошкольного возраста с различными условиями воспитания стала основой нашего исследования. 
Знания и представления детей о структуре и функционировании лица и тела

Таблица 1 (в \% от общего числа респондентов)

\begin{tabular}{|c|c|c|c|c|c|c|}
\hline & \multicolumn{3}{|c|}{ Экспериментальная группа (n=80) } & \multicolumn{3}{|c|}{ Контрольная группа (n=85) } \\
\hline & \begin{tabular}{|c|} 
Самостоятельно \\
ориентируется (\%) \\
\end{tabular} & \begin{tabular}{|c|} 
Использует помощь \\
взрослого (\%)
\end{tabular} & \begin{tabular}{|c|} 
Не ориенти- \\
руется (\%)
\end{tabular} & \begin{tabular}{|c|} 
Самостоятельно \\
ориентируется (\%)
\end{tabular} & \begin{tabular}{|c|} 
Использует помощь \\
взрослого (\%)
\end{tabular} & \begin{tabular}{|c|}
$\begin{array}{c}\text { Не ориенти- } \\
\text { руется (\%) }\end{array}$ \\
\end{tabular} \\
\hline Части лица & 50 & 34 & 16 & 98 & 2 & 0 \\
\hline Части тела & 46 & 39 & 15 & 94 & 4 & 2 \\
\hline $\begin{array}{l}\text { Органы } \\
\text { восприятия }\end{array}$ & 30 & 42 & 28 & 86 & 11 & 3 \\
\hline $\begin{array}{l}\text { Соотнесение } \\
\text { одежды и обуви } \\
\text { с частями тела }\end{array}$ & 37 & 48 & 15 & 98 & 2 & 0 \\
\hline
\end{tabular}

\section{Материалы и методы}

В исследовании приняло участие 165 дошкольников младшего и среднего дошкольного возраста $(3,2 \pm 0,7)$. В экспериментальную группу вошло 80 дошкольников из детского дома. Лишь $15 \%$ из них оказались в Доме ребёнка вследствие смерти или инвалидности родителей. $85 \%$ - это дети, родители которых были либо лишены родительских прав, либо сами отказывались от детей. Таким образом, неблагоприятная ситуация развития этих детей присутствовала ещё до того, как они попали в Дом ребёнка.

Контрольную группу исследования составили 85 дошкольников, проживающих с родителями и посещающих дошкольные образовательные учреждения.

По итогам пилотажного исследования был подобран психодиагностический комплекс, который включал в себя: опросник «Моё лицо и тело»; методики «Собери человека из отдельных частей», «Одень куклу». Проводилось стандартизованное наблюдение в трёх ситуациях: свободная игра, специально организованная подвижная игра, тактильный контакт наблюдателя с ребёнком во время массажа.

\section{Обсуждение результатов}

На первом этапе исследования мы определяли уровень знаний и представлений детей о структуре и функционировании своего тела. Полученные результаты представлены в табл. 1.

Как видно из табл. 1, дошкольники из Дома ребёнка хуже отвечают на вопросы экспериментатора относительно частей лица и тела, чем дети, проживающие с родителями. Так, показывает и называет все части лица лишь половина детей-сирот (50\%), в то время как среди детей, проживающих в семьях, это могут сделать практически все (лишь $2 \%$ испытуемых не смогли справиться с заданием, но хорошо использовали подсказку взрослых).
Осознание частей лица - важный компонент телесной идентичности. В дошкольном возрасте центральной линией развития выступают эмоции, которые на данном этапе могут осознаваться, а, значит, и контролироваться. Осознавать части своего лица - значит, осознавать и изменения с ними во время переживания тех или иных эмоций, а также уметь распознавать чувства других людей по мимическим признакам. Ребёнок, который не может назвать и показать части своего лица, испытывает серьёзные трудности и с осознаванием, контролем над своими эмоциями, и с пониманием чувств другого человека с целью адекватного реагирования в ситуации общения с ним.

Ноги, руки, живот и другие части тела смогло показать на себе меньше половины детей-сирот (лишь 46\%), а среди семейных детей это сделало подавляющее большинство (94\% респондентов контрольной группы). Осознание своего тела целиком определяет способность человека чувствовать и понимать потребности своего тела и организма. Положительное отношение к телу, кроме этого, детерминирует также позитивную самооценку, бережное отношение к физическому здоровью. В дошкольном возрасте осознание тела связано с осознанием половой принадлежности, морфологических отличий в строении тела мальчиков и девочек. Следовательно, проблемы с осознанием частей своего тела могут обуславливать проблемы полоролевого развития ребёнка, усвоение им той или иной гендерной модели поведения, а также его морально-нравственной основы. Как показывают результаты нашего исследования, больше половины детей-сирот могут столкнуться с такими трудностями.

Необходимость назвать и показать органы восприятия оказалась для дошкольников ещё более трудной задачей, лишь третья часть сирот смогла справиться с ней (30\%) против 86\% детей, проживающих в семьях. Знание и осознание органов восприятия обуславливает полноту чувственных впечатлений, получаемых ребёнком со стороны внешнего мира. Они определяют также возмож- 


\section{Психология и психотехника 2(89) • 2016}

Таблица 2

Уровень сформированности телесных реакций у детей (в \% от общего числа респондентов)

\begin{tabular}{|l|c|c|c|c|c|c|}
\hline \multirow{2}{*}{$\begin{array}{c}\text { Наблюдаемые признаки и уровень } \\
\text { их сформированности }\end{array}$} & \multicolumn{2}{|c|}{ Экспериментальная группа (n=80) } & \multicolumn{3}{|c|}{ Контрольная группа (n=85) } \\
\cline { 2 - 7 } & Выс. & Сред. & Низ. & Выс. & Сред. & Низ. \\
\hline $\begin{array}{l}\text { Признаки движения, пульсации, телесной реакции на тепло } \\
\text { (по О.В. Залесской) }\end{array}$ & 59 & 34 & 7 & 98 & 2 & 0 \\
\hline Признаки расслабленности семи сегментов тела (по В. Райху) & 54 & 41 & 5 & 97 & 3 & 0 \\
\hline Признаки построения движений (по Н.А. Бернштейну) & 46 & 51 & 3 & 99 & 1 & 0 \\
\hline
\end{tabular}

ности гибкого поведенческого реагирования при опоре на все органы чувств, доверии им, осознании их роли и значимости. Неумение показать и назвать органы чувств может приводить к проблемам ориентировки в пространстве, трудностям физического развития. Так, две трети дошкольников-сирот, согласно нашему исследованию, могут столкнуться с этими сложностями.

Какая одежда и обувь, к каким частям тела относится, смогла указать лишь часть детей-сирот (37\%). Понять, что перчатки относятся к рукам, а носочки - к ногам, смогли почти все дети. Но соотнести различные виды обуви, одежды, головных уборов, смогли только дети, которые живут с родителями и имеющие большое количество контактов с другими детьми и взрослыми в разнообразных ситуациях (98\%).

Умение соотносить одежду с теми или иными частями тела, в первую очередь, говорит о готовности к самообслуживанию ребёнка, готовности самостоятельно, без помощи взрослого, одеться и обуться. Эти навыки укрепляют уверенность дошкольника в себе, усиливают чувство независимости и самостоятельности, которые так необходимы для него в этом возрасте. Как показывают наши исследования, лишь четверть детей-сирот обладают ими, что может свидетельствовать не только о проблемах самообслуживания, развития инициативы, самостоятельности ребёнка, но и задержке развития мышления.

Следующим этапом нашей работы было изучение различных телесных реакций у детей путём целенаправленного наблюдения. Анализ теоретических и практических работ позволил выделить 3 основных направления изучения телесности [1; 5; 9]: (1) способность принимать тепло (как физическое, так и психическое); (2) наличие мышечных блоков, сковывающих свободное течение энергии в теле, и соответствующую им проблематику; (3) реализация технических компонентов движений (тонус, иннервация, реципрокное торможение, сложные синергии).

В каждом из этих направлений фиксировалась та или иная степень выраженности наблюдаемого признака, которая оценивалась в баллах от 0 до 5 .

(0-1) - низкий уровень сформированности;
(2-3) - средний уровень сформированности;

(4-5) - высокий уровень сформированности (является нормативным).

Как видно из табл. 2, у всех детей контрольной группы высокая степень сформированности движения, пульсации, телесной реакции на тепло. Следовательно, эти дети умеют гармонично взаимодействовать с окружающим миром и с самими собой. У них оптимальные показатели активности, поведенческой и мыслительной гибкости, возможности конструктивно общаться с другими людьми, а в случае необходимости возможности отказаться от интеракции вообще.

В целом хороший уровень сформированности анализируемых нами признаков можно отметить и в экспериментальной группе, где лишь треть всей выборочной совокупности находится на среднем уровне сформированности двигательных функций. Именно эта часть выборки нуждается в оказании коррекционно-развивающей помощи психолога, так как их активность, поведенческая и мыслительная гибкость, умение вступать в конструктивные отношения с другими людьми, уважать свои и чужие личные границы не всегда проявляются адекватно ситуации, что способно порождать ряд социальнопсихологических и внутриличностных проблем.

В ходе нашего исследования не было обнаружено проблем с мышечным напряжением в той или иной области тела у детей контрольной группы. Это свидетельствует о том, что у ребёнка телесные напряжения и расслабления приближены к физиологической норме. Эти дети способны свободно и адекватно сложившимся обстоятельствам выражать свои чувства, они не подавляют их, не зажимают в себе. В таком случае можно говорить об эмоциональном здоровье, хорошем уровне стрессоустойчивости.

В экспериментальной группе у подавляющего большинства детей также отсутствуют признаки мышечного напряжения в каком-либо из семи выделенных В.Райхом секторе тела, что свидетельствует о хорошей жизненной энергии, способности конструктивно выражать эмоции, взаимодействовать с окружающими людьми. Небольшая часть (5\%) детей этой группы, тем не менее, иногда сталкивается с трудностями, связанными с мышечным напряжением, неумением выразить свои чувства 
без вреда для себя и окружающих. У этих детей мышечные напряжения преобладают, но не доминируют, что обуславливает периодическое возникновение трудностей и с эмоциональной стабильностью, и с взаимодействием со взрослыми и сверстниками, и с гармоничным развитием личности в целом.

Эти дети нуждаются в дополнительной работе специалистов, в том числе и психолога-практика, который сможет научить ребёнка выражать свои эмоции адекватно ситуации, снять мышечное напряжение, научиться релаксировать, конструктивно взаимодействовать с окружающими людьми.

У всех детей контрольной группы хороший уровень развития мимики и пантомимики. Следовательно, такие дети могут адекватно выражать свои эмоции и использовать телесную экспрессию для этого. Нормативная степень сформированности всех уровней, выделенных Н.А. Бернштейном, свидетельствует также и о том, что у детей есть все предпосылки для хорошего развития речи и письменности, а также когнитивного развития и развития мотивационно-потребностной сферы личности.

Практически половина детей экспериментальной группы (51\%) демонстрирует средний уровень сформированности движений, выделенных Н.А. Бернштейном. Эти дети могут сталкиваться с проблемами в мимическом, пантомимическом выражении своего психического состояния, что с одной стороны, связано с трудностями самопонимания, а с другой стороны, самовыражения у этих детей. Им свойственно несоответствие мимического, телесного проявления эмоций и чувств и реально переживаемых аффектов, что обуславливает трудности не только речевого развития, но и формирования умения понимать телесные проявления эмоций других людей, что составляет основу формирования таких чувств, как эмпатия, сопереживание, стремления помочь. Таким образом, эти дети нуждаются в психологической помощи, связанной с деятельностью психолога по развитию телесной идентичности ребёнка посредством работы с мимическим и пантомимическим проявлением актуальных психических состояний. С данной группой детей рекомендуется проводить коррекционные занятия с комплексом целенаправленно подобранных упражнений по развитию телесной идентичности, развитию мимики и пантомимики, речи и др.

\section{Заключение и выводы}

Наше исследование показало возможность изучения уровня сформированности телесной идентификации путём организации целенаправленного наблюдения в трёх ситуациях: свободная игра, специально организованная подвижная игра, тактильный контакт наблюдателя с ребёнком во время массажа. Данный подход наряду с использованием традиционных методик, позволил не только количественно определить степень сформированности того или иного признака, но и наметить пути коррекции, учитывая объективную картину развития ребёнка.

Такой подход особенно важен для детей-сирот, когда специалисты вынуждены брать на себя ответственность за формирование телесного образа ребёнка, так как проблемы с осознанием частей своего тела могут искажать полоролевое развитие ребёнка, усвоение им той или иной гендерной модели поведения. Как показало наше исследование, больше половины детей-сирот могут столкнуться с такими трудностями.

Две трети дошкольников-сирот могут иметь проблемы ориентировки в пространстве, трудности физического развития.

Слабое развитие навыков самообслуживания, недостаточная ориентация в современном материальном мире вещей, отсутствие выбора одежды и обуви, снижает уверенность дошкольника в себе, усиливает чувство зависимости.

Телесные реакции, которые мы фиксировали в нашем исследовании, свидетельствуют о нормативности того или иного аспекта телесного развития ребёнка.

Подавляющее большинство детей, воспитывающихся в семье, демонстрирует нормативный уровень развития телесных реакций. Семейная среда является благоприятной для развития ребёнка, подразумевает большое количество тактильных контактов, эмоционально положительно окрашенных.

В группе детей воспитывающихся в детском доме, лишь у половины из них наблюдается нормативная степень сформированности признаков, у другой половины детей - средняя степень развития, которая свидетельствует о присутствии тех или иных проблем телесной идентичности. В этой группе также присутствует небольшое количество детей с глубокими нарушениями двигательных функций, хроническим мышечным напряжением и т.п., что указывает на необходимость дополнительной комплексной работы с этими детьми группы специалистов.

Основными направлениями такой работы могут быть: формирование восприятия целостного образа тела человека; развитие умений чувствовать собственное тело и адекватно относиться к нему, испытать разнообразные мышечные нагрузки; развитие умений узнавать и показывать части лица и тела на себе, окружающих и на разнообразном материале; способствование снижению эмоционального напряжения, преодолению боязни тактильного контакта. 


\section{Психология и психотехника 2(89) • 2016}

\section{Список литературы:}

1. Эриксон Э. Идентичность: юность и кризис / Пер. с англ. М.: Флинта, 2006. 342 с. (Серия: Библиотека зарубежной психологии.)

2. Татаринцева Н.Е. Теоретико-методологические основы и практика полоролевого воспитания детей дошкольного возраста: Дис. ... д-ра пед. наук. Ростов-на-Дону, 2011. 433 с.

3. Кравцова Е.Е. Психологические новообразования дошкольного возраста // Вопросы психологии. 1996. № 6. С. 64-75.

4. Мухина В.С. Возрастная психология. М.: Академия, 1999. 456 с.

5. Выготский Л.С. Проблемы возраста // Психология. М.: Эксмо, 2000. С. 45.

6. Свистунова Е.В. Ребёнок и болезнь: психологический аспект проблемы // Педиатрия. Приложение к журналу Consilium Medicum. 2010. № 3. С. 29-33.

7. Винникотт Д.В. Маленькие дети и их матери. М.: Независимая фирма «Класс», 1998. 80 с.

8. Малер М.С., Пайн Ф., Бергман А. Психологическое рождение человеческого младенца: симбиоз и индивидуация. М.: Когито-Центр, 2011. 413 с.

9. Шпиц Р.А. Психоанализ раннего детского возраста. М.: ПЕР СЭ; СПб.: Университетская книга, 2001. 159 с.

10. Свистунова Е.В., Шумилова С.В., Нестерова Е.В. Играем и развиваемся: комплексная психотерапия искусством детей дошкольного возраста: Методическое пособие. М.: Форум, 2013. 496 с.

11. Залесская О.В. Особенности образа тела у подростков с психосоматической патологией на примере бронхиальной астмы: Дис. ... канд. психол. наук. М., 2007. 169 с.

12. Райх В. Анализ личности. М.: Эксмо-Пресс, 1999. С. 65.

13. Райх В. Характероанализ. Современная психология. М.: Когито-Центр, 2006. С. 67.

14. Бернштейн Н.А. Физиология движения и активность. М.: Наука, 1990. С. 81.

\section{References (transliterated):}

1. $\quad$ Erikson E. Identichnost': yunost' i krizis / Per. s angl. M.: Flinta, 2006. 342 s. (Seriya: Biblioteka zarubezhnoi psikhologii.)

2. Tatarintseva N.E. Teoretiko-metodologicheskie osnovy i praktika polorolevogo vospitaniya detei doshkol'nogo vozrasta: Avtoref. dis. ... d-ra ped. nauk. Rostov-na-Donu, 2011. 433 s.

3. Kravtsova E.E. Psikhologicheskie novoobrazovaniya doshkol’nogo vozrasta // Voprosy psikhologii. 1996. № 6. S. 64 -75.

4. Mukhina V.S. Vozrastnaya psikhologiya. M.: Akademiya, 1999. $456 \mathrm{~s}$.

5. Vygotskii L.S. Problemy vozrasta // Psikhologiya. M.: Eksmo, 2000. S. 45.

6. Svistunova E.V. Rebenok i bolezn': psikhologicheskii aspekt problemy // Pediatriya. Prilozhenie k zhurnalu Consilium Medicum. 2010. № 3. S. 29-33.

7. Vinnikott D.V. Malen'kie deti i ikh materi. M.: Nezavisimaya firma «Klass», 1998. $80 \mathrm{~s}$.

8. Maler M.S., Pain F., Bergman A. Psikhologicheskoe rozhdenie chelovecheskogo mladentsa: simbioz i individuatsiya. M.: KogitoTsentr, 2011. $413 \mathrm{~s}$

9. Shpits R.A. Psikhoanaliz rannego detskogo vozrasta. M.: PER SE; SPb.: Universitetskaya kniga, 2001. 159 s.

10. Svistunova E.V., Shumilova S.V., Nesterova E.V. Igraem i razvivaemsya: kompleksnaya psikhoterapiya iskusstvom detei doshkol'nogo vozrasta: Metodicheskoe posobie. M.: Forum, 2013. $496 \mathrm{~s}$

11. Zalesskaya O.V. Osobennosti obraza tela u podrostkov s psikhosomaticheskoi patologiei na primere bronkhial'noi astmy: Dis. ... kand. psikhol. nauk. M., 2007.169 s.

12. Raikh V. Analiz lichnosti. M.: Eksmo-Press, 1999. S. 65.

13. Raikh V. Kharakteroanaliz. Sovremennaya psikhologiya. M.: Kogito-Tsentr, 2006. S. 67.

14. Bernshtein N.A. Fiziologiya dvizheniya i aktivnost'. M.: Nauka, 1990. S. 81. 